\title{
Overlapping, Additive and Counterregulatory Effects of Type II and I Interferons on Myeloid Dendritic Cell Functions
}

\author{
Loredana Frasca and Roberto Lande \\ Department of Infectious, Parasitic and Immune-mediated Diseases, Istituto Superiore di Sanità, 00161 Rome, Italy
}

Received 8 April 2011; Accepted 27 September 2011

Academic Editor: Fulvio D’Acquisto

Dendritic cells (DCs) are central player in immunity by bridging the innate and adaptive arms of the immune system (IS). Interferons (IFNs) are one of the most important factors that regulate both innate and adaptive immunity too. Thus, the understanding of how type II and I IFNs modulate the immune-regulatory properties of DCs is a central issue in immunology. In this paper, we will address this point in the light of the most recent literature, also highlighting the controversial data reported in the field. According to the wide literature available, type II as well as type I IFNs appear, at the same time, to collaborate, to induce additive effects or overlapping functions, as well as to counterregulate each one's effects on DC biology and, in general, the immune response. The knowledge of these effects has important therapeutic implications in the treatment of infectious/autoimmune diseases and cancer and indicates strategies for using IFNs as vaccine adjuvants and in DC-based immune therapeutic approaches.

KEYWORDS: IFNs, dendritic cell effector functions, immune activation, immune regulation, crossregulation 


\section{BIOLOGICAL FUNCTIONS OF TYPE II AND TYPE I IFNs}

IFNs were discovered more than 50 years ago as factors with the capacity to inhibit viral replication. IFNs were subsequently distinct and classified as type I and type II IFNs [1]. Type I IFNs are a family composed by 13 IFN- $\alpha, 1$ IFN- $\beta, 1$ IFN- $\varepsilon$, and $1 \mathrm{IFN}-\kappa$. All cells are able to release type I IFNs following viral infections, and all cells express the specific receptors composed of IFNR1 and IFNR2 chains. Type II IFN is composed of only one gene product: IFN $-\gamma$. IFN- $\gamma$ was initially named "immune IFN" because it was produced by lymphocytes stimulated with immune stimuli. IFN- $\gamma$ is essential against intracellular fungi, bacteria, and protozoa and for this reason was also named "macrophage activating factor (MAF)." Type II IFN binds to a receptor composed of ubiquitously expressed IFNGR1 and IFNGR2 chains [2].

\section{TYPE II AND I IFNs AND THE IMMUNE SYSTEM}

Type II IFN, referred to as interferon- $\gamma$ (IFN- $\gamma$ ), is an important mediator of immunity and inflammation that utilizes the Janus kinase (JAK) signal transducers and activators of transcription (STAT) signaling pathway [3].

Upon activation of the IFN- $\gamma$ receptor (IFNGR), the phosphorylation of the latent cytoplasmic STAT1 on tyrosine 701 stabilizes a STAT1 dimer, formed by STAT1 monomers in a parallel configuration. STAT1 can, therefore, translocate to nucleus, where it binds to cognate DNA sequences and activates transcription of STAT1 target genes. Active STAT1 in the nucleus undergoes acetylation (for regulation of these processes see, Krämer and Heinzel [4]).

IFN- $\gamma$ has multiple functions in immunity (for review see, [5]). Key functions are often mediated by cross-regulation of cellular responses to other cytokines and inflammatory factors. This cross-regulation has important functional implications for immune cell activation, production of cytokine, inflammatory responses, tissue remodeling, T-cell differentiation, and for autoimmune diseases [5]. IFN- $\gamma$ plays decisive role in T-helper (Th)-1 polarization [6,7], stimulates DCs and macrophages effector functions [6], upregulates proinflammatory factors (IL-12, IL-15, TNF-, IFN-inducible proteins, IP-10/CXCL10, Mig/ CXCL9, and I-TAC/CXCL11) and inducible nitric oxide sintetase [6,7], exerts an important "priming" effect on the induction of IL-12p70 by monocytes $[6,7]$ and DCs [8]. These activities, mainly studied in vivo, highlight a proinflammatory role of this cytokine, supported by the use of IFN- $\gamma$ - and IFNGRknock-out mice that have confirmed the critical role of IFN- $\gamma$ in Th-1 immunity largely using intracellular pathogens as infectious models (reviewed in [7, 9]). However, the use of the same in vivo models provide evidence indicating that IFN- $\gamma$ is also a master regulator of immune response and inflammation, a concept witnessed by evident beneficial effects in experimental systems of autoimmunity (reviewed in [10, 11]). Anti-inflammatory/regulatory effects include regulation of B-cell motility [12] and T-cell survival [13], regulatory T-cell activation [14], and, more recently, suppression of Th-17 polarization [15, 16]. We have recently undertaken a wide analysis of the IFN- $\gamma$ effects on human DCs functions [17], since these cells are central player in immunity.

Type I IFNs, namely, IFN- $\alpha$ and IFN- $\beta$, are also important regulators of immunity and possess, similarly to IFN- $\gamma$, both proinflammatory and anti-inflammatory effects $[18,19]$. These IFNs are also able to signal via STATs activation (for review, see $[3,19]$ ). It is not completely clear whether these two type I IFNs $(\alpha$ and $\beta$ ) have absolutely identical effects in immunity. Indeed, as general practice, IFN- $\beta$ is often used to suppress autoimmunity, especially in multiple sclerosis (MS) [18], whereas IFN- $\alpha$ has mainly been used to activate protective immune responses in infectious diseases, (especially in HCV infection) [20 22 ] and in cancer therapy to condition monocyte-derived DCs (MDDCs) to be used for vaccine purpose [23-25].

In this paper we would like to review the current literature about the effect of type II IFN on both human and mouse DCs and to point out all the similarities and differences between the effect of type II and type I IFNs, the latter also possessing a crucial impact on the DC biology [19]. Contrasting observations have often been reported in the literature regarding the outcomes of both type II and I stimulation of DCs. 
TABLE 1: Type II and I IFN overlapping effects on dendritic cells. The scheme depicted resumes the most important overlapping effects of type II and I IFNs on DCs. Numbers refer to references as reported in the References section.

\begin{tabular}{lll}
\hline IFN- $\gamma$ & IFN- $\gamma$ and IFN- $\alpha / \beta$ overlapping effects & IFN- $\alpha / \beta$ \\
\hline$[17,26,27]$ & Potentiate CD40L stimulation of DCs & {$[2,28-32]$} \\
{$[17,33]$} & Potentiate CD8 T-cell stimulation by DCs & {$[34]$} \\
{$[17,21,33]$} & Potentiate IFN- $\gamma$ production, by cocultured T cells & {$[17,21,33]$} \\
{$[17,26,27,32,35]$} & Potentiate IL-12p70 and IL-6 production, by DCs & {$[17,26,27,32,35]$} \\
{$[17,21]$} & $\begin{array}{l}\text { Potentiate CCR7-driven migration of DCs } \\
\text { (controversial) }\end{array}$ & {$[24,25,32,36,37]$} \\
{$[17,38,39]$} & Induce CD38 in DCs & {$[28,40]$} \\
{$[26,27,35,41,42]$} & Stimulate production of CXCL9 and CXCL10 by DCs & {$[24,25,43]$} \\
{$[8,44-48]$} & Can block APC capacity of DCs (via expression of & {$[49]$} \\
{$[8,50]$} & B7-H1 and IDO by DCs) & {$[2,28,51-58]$} \\
{$[17,26,27]$} & Potentiate IL-27 production by DCs, reduce OPN & {$[59,60]$} \\
{$[61-64]$} & Upregulate MHC class I (and II) molecules in DCs & {$[61,62,65-70]$} \\
To be tested & Increase IL-15 production and transpresentation by & {$[60]$} \\
Frasca and Lande, unpublished & DCs & Frasca and Lande, \\
& Increase T and NK cells activation and maintenance & unpublished $[63,71]$ \\
\hline
\end{tabular}

TABLE 2: Type II and I IFN additive, opposite and counter-regulatory effects on dendritic cells. The scheme depicted resumes the most important overlapping, additive, opposite and counter-regulatory effects of type II and I IFNs on DCs. Numbers refer to references reported in the References section.

\begin{tabular}{|c|c|c|}
\hline IFN- $\gamma$ & & IFN- $\alpha / \beta$ \\
\hline Potentiates for cancer therapy $[23,24,37]$ & + & Potentiate for cancer therapy $[23,24,37]$ \\
\hline Diminishes IL-10 and STAT3, by DCs [16] & $\neq$ & Increase IL-10 production, by DCs $[72,73]$ \\
\hline $\begin{array}{l}\text { Inhibits IL- } 1 \beta \text { production by mouse DC and } \\
\text { increases IL- } 1 \beta \text { in human DCs }[74,75]\end{array}$ & $\neq$ & $\begin{array}{l}\text { Inhibit IL- } 1 \beta \text { production by both mouseand } \\
\text { human DCs }[74,75]\end{array}$ \\
\hline Regulate response to itself $[76,77]$ & cb & Regulate response to themselves [78] \\
\hline $\begin{array}{l}\text { IFN- } \gamma \text { effects counteracted by IFN }-\alpha / \beta \\
{[31,79]}\end{array}$ & co & $\begin{array}{l}\text { Inhibit IL- } 12 p 70 \text { production by mature DCs } \\
\text { and IFN- } \gamma \text { effects on DCs irrespective of thier } \\
\text { maturation status }[31,79,80]\end{array}$ \\
\hline $\begin{array}{l}\text { Response to IFN- } \gamma \text { regulated by type I IFN } \\
\text { both in vitro }[31,79,80] \text { and in vitro }[81-83]\end{array}$ & co & $\begin{array}{l}\text { Inhibit IFN- } \gamma \text { production in vivo by down } \\
\text { regulation of IFN- } \gamma \text { receptor }[84,85] \text { or } \\
\text { up-regulation SOSCS1 }[83] \text { in DCs }\end{array}$ \\
\hline
\end{tabular}

+ Additive, $\neq$ opposing, $\boldsymbol{C}$ o counterregulatory, effects on DCs.

Moreover, differences between the human and mouse systems also occur. All the overlapping effects on DCs of both IFN types are resumed in the scheme in Table 1.

Lastly, since it is known that type I and II IFNs can antagonize each other's effect in vivo [19], we discuss this counterregulation in the particular context of DC activation. Counter-regulatory effects of IFNs on DCs as well as differences between type II and I IFNs and opposite effects are resumed in the scheme in Table 2. 


\section{INTERFERON- $\gamma$ EFFECTS AND AUTOCRINE IFN- $\gamma$ LOOP IN MYELOID DENDRITIC CELLS}

Many researchers have studied IFN- $\gamma$ effects on one of the most important cell of the immune system, the DCs. This has also provided some clues about the use of IFN- $\gamma$ (together or in alternative to type I IFNs) in protocols that use DCs as a tool for human therapeutic vaccines to cure tumors or chronic infections [23, 25].

Many of these studies have used DCs generated by culture of blood monocytes in the presence of GM-CSF and IL-4 [24] (MDDC), with some exceptions [22, 25].

\subsection{IFN- $\gamma$ Renders DCs Able to Potentiate Th-1- and CD8 T-Cell Responses}

The most classical believe is that IFN- $\gamma$ represents an activating stimulus that potentiates multiple DC tasks. For instance, the concerted action of CD40 triggering and IFN- $\gamma$ stimulation is uniquely required for high IL-12p70 production by DCs $[17,25,26,86]$. We have addressed the outcomes of IFN- $\gamma$ stimulation on a wide array of MDDC effector functions, when the cytokine was used alone or in combination with classical stimuli (Toll-like receptor (TLR)-4 or CD40 stimulation) [17]. IFN- $\gamma$ alone given to MDCCs was able to upregulate various maturation markers (CD80/86, MHC molecules, CCR7) and at lower, but significant extent CD83. It also protects MDCCs from spontaneous apoptosis [17] via upregulation of the prosurvival factor Bcl-2 [87], a molecule that is usually upregulated in mature DCs, whereas the proapoptotic molecule Bax was downregulated. Indeed, IFN- $\gamma$ increased Bcl-2: Bax ratio to levels comparable to those achievable after Lipopolysaccharide (LPS) treatment or CD40 triggering, both stimuli increasing MDDC half-life.

We also addressed IFN- $\gamma$ signaling in MDDCs by analysing STAT1 and STAT3, all MAPKs, and $\mathrm{I} \kappa \mathrm{B} \alpha$, the NF- $\kappa \mathrm{B}$ inhibitor. Regarding STATs, western blot analysis showed STAT1 phosphorylation induced very early by IFN- $\gamma$, earlier than upon CD40 triggering or LPS stimulation. STAT1 activation tended to be enhanced upon double stimulation (coupled with LPS administration or CD40 triggering), whereas STAT3 phosphorylation decreased. It is known that STAT3 inhibits full upregulation of DC maturation markers and IL-12p70 secretion [88-90]. Thus, concomitant administration of IFN- $\gamma$ and CD40 (or TLR4) stimulation seemed to relax the STAT3-mediated inhibitory activity on antigen-presenting cell (APC) functions, favoring a sort of "hyperactivation" of DCs. This effect, promoted by IFN- $\gamma$ stimulation (when maturation stimuli are also provided), can be beneficial in cancer therapy, a setting in which immune regulatory/suppressible mechanisms should be relaxed.

Despite IFN- $\gamma$ provided alone to DCs was able to induce an apparent mature phenotype and CCR7upregulation, this was not sufficient neither to gain an efficient APC capacity in mixed lymphocyte reactions (MLR) nor to migrate in response to CCL21 in vitro [17]. Culture with IFN- $\gamma$-treated DCs (as compared with untreated DCs) only increased the subsequent capacity of a mix population of CD4 and CD8 T cells to kill target cells in a classical cytotoxic assays. However, this was not the case when purified CD8 T cells were used. We interpreted these data by assuming that when both CD4 and CD8 T cells were present in culture, CD4 T cells that expressed CD40L (unlike the CD8 T cells) might have provided a further input, in addition to IFN- $\gamma$ signaling, so that the cytotoxic activity could be enhanced in a subsequent rechallenge with cognate targets. CD40L stimulation provided by the cocultured CD4 T cells and the prior exposure to exogenous IFN- $\gamma$ may have worked together by increasing membrane-bound IL-15 on the DC surface so that the killer cells resulted are more efficient in killing (see below, [65]).

Although we have not performed the experiment, it is possible that the cytotoxic activity of cocultured T cells might also be implemented whether IFN- $\gamma$ is used in combination with LPS with respect to either stimulus alone. A recent paper [33] has shown that IFN- $\gamma$ helps DCs to gain the function to activate CD8 T cells independently of CD4 T-cell help. Interestingly, the authors also demonstrated that LPS alone would prime CD8 T cells in the absence of CD4 T-cell help by inducing an endogenous production of IFN$\gamma$ that is required for this function [33]. In the same study, IFN- $\gamma$ was also shown to restore APC functions of DCs after mycophenolic acid treatments [33].

Through all of our work [16], IFN- $\gamma$ treatment was shown to further enhance several functions already gained by DCs following classical maturation stimuli administration (LPS, CD40L). The final idea 
was that IFN- $\gamma$ could "arm" multiple MDDC effector functions, in part (as already shown through the wide literature in this field), by reinforcing MDDC Th- 1 stimulatory ability, capacity to attract CXCR3 ${ }^{+}$Th- 1 cells [26, 27, 33, 35, 41] and to increase CCR7-driven migratory behaviors [17].

\subsection{IFN- $\gamma$ Can Effect CCR7-Driven Migration of DCs}

IFN- $\gamma$ upregulates CCR7 on MDDCs, the specific receptor for CCL19/CCL21 chemokines expressed in the lymph nodes. However, it is well known that CCR7 expression does not always guarantee acquisition of CCL19/CCL21 responsiveness [91]. When we assessed CCL21-driven chemotaxis of IFN- $\gamma$-treated MDDCs, we found that they were not able to migrate towards this chemokine gradient. Their capacity to sense CCL21 was, however, obtained when IFN- $\gamma$ was given coupled with TLR-4 or CD40 activation. The double stimulation rendered MDDCs even more prone than MDDCs treated with the sole LPS or CD40 stimulation, to migrate towards CCL21. It should be mentioned that one report showed that IFN$\gamma$ acted to actually inhibit CCR7-driven migration of MDDCs, when added to the classical maturation cocktail used in cancer therapy and containing prostaglandin E2 (PGE2) [92]. It is possible that differences in the maturation stimuli used (cytokines instead of TLR-stimulators), or conditions maintaining IL-4 in culture, may account for this opposite result. However, other works (for review, see [23]) showed that a new "type I polarizing cocktails," containing both type II and I IFNs, did not block, but only slightly decreased, CCL21- and CCL19-driven migration of human DCs, as compared to the classical PGE2-containing cocktail, demonstrating that IFNs do not always inhibit CCR7-driven migration.

\subsection{IFN- $\gamma$ Induces CD38 on DCs, a Molecule That Implements Various DC Effector Functions, Included CCR7-Driven Migration}

The increased efficiency of CCR7-driven migration determined by IFN- $\gamma$ revealed a further level of "enhancer/regulatory effect" of this IFN on human DC functions. Since this phenomenon occurs as a priming effect too, a fashionable interpretation was that IFN- $\gamma$ can prepare the DCs in the tissue for a subsequent migration step, which can be induced subsequently either by stimulation with TLR-binding factors (for instance LPS) or crosstalk with effector CD4 T cells that have homed to the inflamed tissues (and can provide CD40 stimulation). Our initial studies had shown that IFN- $\gamma$ is a stimulus that induces CD38 on human MDDCs [38]. We then discovered that stimulation of CD38 helps CCR7-driven migration [39]. Interestingly, concomitant IFN- $\gamma$ stimulation and triggering of CD38 consistently increased CCL21-driven migration [17]. Thus, IFN- $\gamma$ can equip the DCs with this further receptor (CD38) that can implement DC trafficking towards the lymph nodes (LNs). However, we have also demonstrated that CD38 on DCs is able to implement other effector functions [17, 39]. For instance, concomitant stimulation with IFN- $\gamma$ and via the CD38 receptor increases IL-12p70 secretion by DCs [38] and IFN- $\gamma$ production by cocultured T cells [17]. The same type of stimulation also enhances MDDC capacity to recruit activated Th-1 cells, suggesting a synergy between IFN- $\gamma$ and CD38 signaling in inducing release of CXCR3-binding inflammatory chemokines. These novel findings suggest important implications of CD38 signaling in the process of inflammation. This is even more relevant considering that CD31, the CD38 counterreceptor, is expressed not only by the DCs themselves but also by various parenchymal, endothelial, and B cells residing in, or homing to, inflamed tissues. More intriguingly, CD31 is peculiarly expressed by naive T cells [72, 93] that encounter DCs in LNs. Thus, it is conceivable to see CD38 signaling as an additional "licensing stimulus" that inflamed tissues or LN environments confer to mature DCs or DCs conditioned by IFN- $\gamma$, expressing high CD38 levels. This idea is now even more fashionable given the results of a recent work by MarelliBerg's group [72] that has discovered a novel function of CD31 signaling in naive T cells. These authors showed that CD31 is a nonredundant comodulator of T-cell responses, which is specialized in sizing the immune response by setting the threshold for T-cell activation and tolerance. Signaling of this molecule can also prevent memory T-cell death. Although CD31 can also be triggered via homotypic interaction with other CD31 molecules expressed on APCs or parenchymal cells, it is very likely that interaction with 
CD38 can take over once the APCs (namely the DCs) are in a mature state and express high level of CD38, allowing CD38 to regulate the level of activation of T cells. The role of this interaction deserves a more detailed investigation to complete the preliminary scenario depicted in this study [72]. In conclusion, a further pivotal effect of type II IFN is to equip DCs with an important receptor that can regulate both DCs and T-cell activity. Interestingly, as discussed below, this appears a property shared with type I IFN in that also IFN- $\alpha$ can upregulate CD38 on human DCs [28].

\subsection{IFN- $\gamma$ Regulates IL-27 and Other Factor Expression by DCs and, Indirectly, IL-17 Production by T Cells}

IL-27 is a heterodimeric cytokine composed by an IL-12p40-related protein (Epstein-Barr virus-induced gene 3, EBI3) and by an IL-12p35-related polypeptide (p28). This cytokine is produced by antigenpresenting cells (APCs) and signals through a receptor containing the common IL-6 receptor chain gp130 and the unique IL-27 receptor $\alpha$ chain (WSX-1), expressed on T and B cells, natural killer (NK) cells, mast cells, monocytes/macrophages, DCs, and endothelial cells. IL-27 was initially described as a proinflammatory cytokine, sensitizing lymphocytes to IL-12 and, thus, promoting Th-1 responses and as enhancer of NK activity. Recently, other functions of IL-27 have been described, included a role in inducing IL-10-producing $\operatorname{Tr} 1$ cells (for review, see [94]).

A novel observation of our recent studies showed that treatment of human DCs with IFN- $\gamma$ could increase production of the p28 subunit of IL-27 and that priming with IFN- $\gamma$ or INF- $\gamma$, provided during maturation, led to increase of both IL-27 subunit transcription (p28 and EBI3) in MDDCs [17]. IFN- $\gamma$ had previously been shown to suppress IL-17 production both in vitro and in vivo [8]. Since IL-27 had also been shown to suppress Th-17 in vivo [28], it was possible that IFN- $\gamma$ could restrict Th-17 cell activation via an indirect action on the APCs (the DCs), through enhancing the secretion of IL-27. The lack of in vitro tools to measure IL-27 release in vitro by IFN- $\gamma$-conditioned DCs did not allow to indicate this mechanism as really operative. However, we found that small amounts of IL-17 were produced by T cells that had been cultured with DCs matured via CD40 ligation and that IL-17 was not secreted when T cells were instead cultured with DCs stimulated via both CD40 triggering and IFN- $\gamma$ conditioning, a type of culture that greatly stimulated IL-27 mRNA transcription. Thus, it was likely that IFN- $\gamma$ conditioning of DCs rendered them more prone to secrete high quantity of IL-27, so that the Th-17 cells interacting with those DCs were refrained from expanding. Subsequently, this hypothesis has been corroborated in vivo. Indeed, an interesting recent paper [50] has shown that INF- $\gamma$ induces IL-27 secretion by mouse DCs, as measured both at RNA and protein level and that engagement of IFNGR on DCs is responsible for suppressing IL-17 production by responder $\mathrm{T}$ cells both in vitro and in vivo. Thus, these authors have shown a link between IFN- $\gamma$ stimulation of DCs and inhibition of Th-17 cell induction/expansion, acting via IL-27 production by the DCs themselves. In addition, the same study showed that IFNGR engagement on DCs concomitantly inhibited osteopontin (OPN), a factor that possesses potent inflammatory functions $[95,96]$ and induces Th-17 cells in MS patients [96]. Thus, Murugaiyan et al. have discovered an additional interesting mechanism by which IFN- $\gamma$ limits IL-17-mediated autoimmune inflammation via the reciprocal regulation of IL-27 and OPN expression in mouse DCs. Indeed, IFN- $\gamma$ inhibits OPN while it upregulates IL-27. Another recent paper also supports these data about capacity of IFN- $\gamma$ and IL-27 to limit autoimmune inflammation, showing that IFN- $\gamma$ and IL-27 can also regulate autoimmune arthritis. If present at the onset of the diseases, IFN- $\gamma$ and IL-27 can block IL-17 secretion [74].

Inhibition of Th-17 cells in a mouse system of tuberculosis infection was recently shown to depend on another effect induced by IFN- $\gamma$ priming in DCs, that is, the reduction of IL- $1 \beta$ secretion by the DCs themselves. Lack of IL- $1 \beta$ impaired IL-17 production by splenocytes [75] in this setting. In the same model system, the action of IFN- $\beta$ was also investigated. IFN- $\beta$ exerted an effect similar to that of IFN- $\gamma$, because it also interferes with IL- $1 \beta$ production and subsequent Th-17 cell stimulation. Interestingly, IFN- $\beta$ has been shown to decrease IL- $1 \beta$ and IL-17 production in human cells as well [97]. However, IFN- $\gamma$ priming, before Mycobacterium tuberculosis (MTB) stimulation, was shown to induce IL- $1 \beta$ in human MDDCs [75], 
revealing possible differential effects of type I and II IFNs on secretion of this cytokine in the human cells. Such induction of high IL- $1 \beta$ in DCs by IFN- $\gamma$ in humans may explain, according to the authors of the latter paper, the way IFN- $\gamma$ is detrimental in MS.

\subsection{INF- $\gamma$ Can Also Have a Regulatory/Suppressor Effect on DC Activity}

It should be pointed out that effects exerted by IFN- $\gamma$ appear very different whether this cytokine is administered to fully differentiated/maturing DCs or to monocyte during the differentiation process into DCs. Indeed, the exposure of monocytes to IFN- $\gamma$, during the differentiation process towards DCs, has been shown to either yield macrophages or induce a state of poor APC stimulatory ability or tolerogenic effects mediated by the resulting DCs $[8,44,45]$. Regarding this latter phenomenon, previous papers had focused on regulatory effects of IFN- $\gamma$-"modified" DCs in vivo. Shinomiya et al. [46] demonstrated that the injection of IFN- $\gamma$-stimulated DCs in vivo prevented the onset of diabetes in NOD mice. Similar results were reported in another paper [47]. In the latter study, the use of tryptophan-metabolizing enzyme indoleamine 2,3dioxygenase (IDO) inhibitor methyl-thiohydantoin-tryptophan (1MT), an inhibitor of IDO [98], allowed to show that the inhibitory effect was due to IDO activation. Indeed, IDO activation is reported to be an important inhibitory factor of T-cell activation induced by IFN- $\gamma$ treatment in various type cells, included DCs $[98,99]$. Another inhibitory molecule, B7-H1 (also called PD-L1) [48] is also induced by IFN- $\gamma$ in monocytes and DCs and may account for some of the observed inhibitory effects of such "IFN- $\gamma$-modified DCs," although the papers cited above $[46,47]$ did not address this aspect. It should be mentioned that also type I IFN is able to upregulate B7-H1 in human DCs [49] (see below). In keeping with these observations made in mouse cells, as already mentioned, DCs treated with the sole IFN- $\gamma$ were not able to a stimulate MLR in our hands either. We did not test B7-H1 expression by our MDDCs treated with the sole IFN- $\gamma$, so we cannot exclude a role for this molecule. Instead, we could not restore the APC capacity of the MDDCs treated with the sole IFN- $\gamma$ [17] by using the IDO inhibitor 1MT, excluding that IDO was responsible for the poor APC stimulatory ability of IFN- $\gamma$-treated DCs in our setting.

\subsection{IFN- $\gamma$ Autocrine Loop in DCs}

We cannot omit to outline that, similar to the type I IFN autocrine loop induced in DCs [77] described in recent years (see below) and shown to activate various DC effector functions, a type II IFN internal loop exists too. The production of IFN- $\gamma$ by mouse DCs in response to infections with intracellular pathogens [100-102] is well established, but the idea that also human DCs can produce IFN- $\gamma$ has not been immediately so popular [103].

In the mouse system the rapid upregulation of T-bet by IFN- $\gamma$ in DCs, coupled with a function for DC-derived IFN- $\gamma$ in T-cell activation, appeared to constitute a positive feedback loop to maximize Th- 1 immunity [104]. Interestingly, it was shown that in human DCs T-bet upregulation can be IFN- $\gamma$ but not type I IFN dependent [105].

Recent papers have demonstrated the existence of the IFN- $\gamma$ loop in human DCs more clearly. Fricke et al. [106] demonstrated that human DCs produced IFN- $\gamma$ at the single cell level by using Bacille calmetteGuérin (BCG) as a model pathogen, which acts via TLR-2 stimulation. The IFN- $\gamma$ loop was shown to contribute to the secretion of proinflammatory factors such as TNF- $\alpha$ and IL-13 by the DCs, and its effects were enhanced by provision of IL-12, IL-15, or IL-18. A similar effect of the IFN- $\gamma$ loop was evidenced by Steinman's group and shown to contribute to accelerate CD8 T-cell proliferation to recall antigen presented by the DCs. Even in this paper, IL-18 was shown to contribute to IFN- $\gamma$ functions by effectively inducing the autocrine IFN- $\gamma$ [107]. According to another study, IFN- $\gamma$ and T-bet can be induced in human DCs through an ERK-dependent pathway [108].

LPS induces IFN- $\gamma$ in myeloid DCs, and such IFN- $\gamma$ is considered crucial to induce CD8 T-cell activation. Indeed, as already mentioned, LPS can induce the licensing of APC for CD8 T-cell priming in 
the absence of CD4 T-cell help, an effect strongly dependent of an IFN- $\gamma$ autocrine loop induced in DCs by LPS itself [33].

\section{INTERFERON- $\alpha / \beta$ EFFECTS AND AUTOCRINE IFN- $\beta$ LOOP IN MYELOID DENDRITIC CELLS: SIMILARITIES AND DIFFERENCES WITH THE IFN- $\gamma$-INDUCED FUNCTIONS}

Type I IFNs, as stated above, are also important regulators of immunity and exert both pro- and anti-inflammatory effects $[3,18,19,19,20]$. Originally, they have been identified for their antiviral activities, but they are currently recognized as signaling molecule providing a link between innate and adaptive immunity. All kinds of cells susceptible to a viral infection can release type I IFNs. However, within the immune system, DCs have the unique ability to recognize and respond to a variety of pathogens by releasing IFNs. Myeloid DCs are also modulated by type I IFNs, produced by other cells or by themselves (autocrine loop, see below).

The outcomes of stimulation of DCs with type I IFNs have been studied by providing IFN- $\alpha$ or IFN$\beta$ after, before, or during the maturation process, with different results (see below). Focusing on type I IFN effects in myeloid DCs (for further review, see [2]), in many studies the separate effect of IFN- $\beta$ or IFN- $\alpha$ has been addressed, whereas in others no distinction has been done. Moreover, after the first discovery of the autocrine IFN- $\beta$ loop in DCs stimulated via particular TLRs $[2,77,109]$ many studies have addressed the importance of this loop in DC biology [29-31]. In some of these studies, it has been shown that IFN- $\beta$ can have similar effect whether it is given exogenously or acts through the endogenous loop. For instance, LPS is a typical stimulus that can induce the IFN- $\beta$ loop necessary for IL-12p70 release and full maturation of DCs; however, type I IFN given exogenously has the same effect [28].

\subsection{IFN- $\alpha / \beta$, Like IFN- $\gamma$, Potentiate the T-Cell Stimulatory Activity of DCs}

Several studies in the literature have shown that IFN- $\alpha$ given during the maturation process has a positive and enhancer activity on myeloid DC functions [2]. Focusing on IFN- $\beta$ only, several studies have analyzed the effects of exogenous provision of this IFN to human DCs. Likewise for IFN- $\alpha$ studies, even in this case, the timing of exposure is important and may induce contrasting effects. For instance, IFN- $\beta$ exposure during TNF- $\alpha$ or other stimuli administration to MDDCs was shown to increase the maturation of these cells and promote Th-1 response generation [28-31]. Enhancer effects consist in induction of maturation markers, elevation of IL-12p70 production by conditioned DCs, and increase of Th- 1 response. However, like IFN- $\alpha$, IFN- $\beta$ appears to inhibit IL-12p70 production by already mature DCs and counteracts the IL12-enhancing effect of IFN- $\gamma$ on DCs irrespective of their maturation status [73, 79] (see below).

With regards to the enhancer effect of type I IFN on DC effector functions, some of the studied outcomes seem similar to, or overlapping with, those elicited by IFN- $\gamma$ [32]. However, there are some differences, and these have been dissected in the past 10-15 years. For all IFNs $(\alpha / \beta$ or $\gamma)$, the encounter with a DC is not a null event. Both stimuli used alone are poor in inducing some kind of maturation $[2,32,36$, 42, 109], but they all potentiate activation signals induced in MDDCs by CD40 triggering [17, 24, 25, 32], including achievement of a fully mature phenotype and high IL-12p70 secretion.

A similarity in the effects produced by both type I and type II IFN stimulation of DCs is that IFN- $\alpha$, like IFN- $\gamma[17,32]$, acts by enhancing the capacity of MDDC to elicit IFN- $\gamma$ production by cocultured allogeneic T cells [42]. Moreover (similarly to IFN- $\gamma$ ), IFN- $\alpha$ can also induce CXCL9 and CXCL10 production by MDCCs, rendering them more able to recruit activated Th- 1 cells [24, 25, 42, 43]. Further potentiating effects on CD8 T-cell activation may depend on the capacity of IFN- $\alpha$ to induce stabilization of MHC class I/peptide complexes [59]. On the other hand, induction of expression of MHC class-I-related chain A and B on DCs may be one of the mechanisms by which IFN- $\alpha$ activates NK cells [60]. 
Regarding effects of both type I and II IFNs on DC-derived cytokines other than IL-12p70, Marakovky's group [32] firstly showed that both IFN- $\gamma$ and IFN- $\alpha$ could increase IL-6 secretion induced by CD40 ligation, whereas only IFN- $\alpha$ could induce more IL-10 in response to the same stimulus. In our hands IFN- $\gamma$ not only did not increase IL-10 secretion but even diminished the production of this cytokine in DCs concomitantly stimulated with LPS or CD40L [17]. Conversely, Coccia's group more recently found IFN- $\beta$ to upregulate IL-10 production after LPS, but not Pam3cis stimulation of MDDCs, showing that the regulation of IL-10 production is not completely regulated by type I IFN but may depend on the type of maturation stimulus concomitantly given to the DCs [28].

\subsection{IFN- $\alpha / \beta$, Like IFN- $\gamma$, Are Able to Induce CD38 on DCs}

As already mentioned, type I IFN is able (similar to IFN- $\gamma$ ) to upregulate expression of CD38 on human DCs [28]. Thus, like IFN- $\gamma, \operatorname{IFN} \alpha / \beta$ are also able to equip the DCs with this molecule now known to contribute to Th-1 activation, CCR7-driven migration, and T-cell recruitment $[17,38,39]$. In this regard, it has been recently shown that inclusion of type I IFN in a new cocktail to activate DCs for immune therapy [110] implemented CD38 expression and, as a consequence, the capacity of DCs to activate T cells increased. CD38 can also be induced by the autocrine IFN- $\beta$ loop [40] such as that induced by TLR-4 stimulation [28]. Interestingly, a pathogen such as Borrelia was not shown to induce this autocrine loop, and, as a consequence, DCs infected by Borrelia were found to be CD38-negative. Accordingly, they possessed an impaired capacity to secrete IL-12 and migrate towards CCL21 and CCL19 gradients [40], both in vivo and in vitro.

\subsection{IFN- $\alpha / \beta$ Can Have Both Activatory and Inhibitory Effects on CCR7-Driven Migration of DCs}

It should be mentioned that contrasting results are reported in the literature regarding migration guided by CCR7 of DCs treated with IFN- $\alpha / \beta$ (controversial results have also been published for IFN- $\gamma$, see previous paragraph). There is large consensus on the fact that CCR7 is not induced by IFN- $\alpha[2,32]$ and- $\beta$ [34] alone. Marakovsky's group [32] had shown that addition of IFN- $\alpha$ during maturation induced by PGE2 and TNF induced a greater migratory ability guided by CCL21 in MDDCs. Other authors have found opposite results, showing that IFN- $\beta$ actually inhibits CCR7-driven migration of DCs and interferes with CCR7 upregulation during maturation of these cells [34]. Such different results are not always easy to explain. Again, in keeping with the positive effect of type I IFN on CCR7-driven migration, are studies on the treatment of monocytes with IFN- $\alpha$ combined with GM-CSF, directly during the differentiation process to MDDCs, to yield the socalled "IFN-DCs". IFN-DCs have been shown to be potent inducer of Th-1 responses. Moreover, they were found to upregulate CCR7 and migrate efficiently towards CCL19 [24, 36]. Recently the group of Kalinski has shown that the inclusion of both IFN- $\gamma$ and IFN- $\alpha$ in the so-called "type I polarizing DCs-cocktail" (as opposed to the actual "gold standard" for DC-based cancer vaccination containing PGE2) yielded DCs that were very good at producing IL-12p70 and eliciting long-lived CTLs against melanoma antigens. This, in contrast with other works, was achieved without a real impairment of the DC ability to migrate towards CCR7 ligands $[2,25,37]$. Thus, the picture is not completely clear, but it appears that type I IFNs can have differential effect on this function depending on how the DCs are concomitantly stimulated.

\subsection{IFN- $\alpha / \beta$ Increment of the Capacity of DCs to Transpresent IL-15, a Cytokine Responsible for T-Cell Activation That Also Ensures T-Cell Memory Maintenance}

Additional IFN- $\alpha$-mediated effects on DCs have been studied in subsequent researches and are also overlapping with those elicited by INF- $\gamma$. An interesting link between type I IFN (and IFN- $\gamma$, see below) and the IL-15 cytokine $[65,66]$ has been discovered. IL-15 plays a pivotal role in promoting survival, proliferation, and activation of NK cells and $\mathrm{CD} 8^{+} \mathrm{T}$ cells and is typically transpresented to the target cells 
by an opposing cell expressing the cytokine on the cell membrane bound to the IL-15R $\alpha$ [65]. DCs represent an important cell type that transpresent IL-15 to T-cell memory [66]. Interestingly, DCs produce IL-15 when stimulated in the presence of IFN- $\alpha[61,67-70]$. We have demonstrated recently that IFN- $\alpha$ could enhance peptide-vaccine-induced CD8 T-cell numbers and effector functions in vivo [61], at least, in part, via increment of IL-15 effects mediated via the DCs. In this model, increased in vivo maintenance of CD8 $\mathrm{T}$ cells specific for a melanoma antigen and with an effector memory phenotype was due not only to IFN- $\alpha$ receptor expression on the CD8 T cells themselves but also to IL-15 upregulation on DCs. Indeed, we have shown that IFN- $\alpha$-conditioned mouse DCs were able to mediate expansion and maintenance of melanomaspecific memory CD8 T cells in vitro, due to increased capacity to transpresent IL-15 [61]. DCs that are activated, in a way to induce the autocrine IFN- $\beta$ loop, also upregulate IL-15 on their cell membrane and become more effective in activating NK cells to kill tumors in vivo. For instance, in the setting analyzed by Boudreau et al. [62], type I IFN was shown to activate another important innate immune cell (the NK cell), via an indirect effect on the DCs, again by inducing IL-15 transpresentation. IL-15 tranpresentation has been shown by us to have an additional role for NK-DC interactions in that DCs also support the development and homeostatic maintenance of these cells. Thus, it is possible that type I IFN may also regulate homeostasis of NK cells and [111] not only their activation and production of IFN- $\gamma$ [88]. In the paper by Kalinski's group [34], in which human DCs treated with a cytokine cocktail containing both type I and type II IFN were shown to possess great T-cell stimulatory ability and induce long-lasting CD8 cytotoxic T cells specific for tumors, the role of membrane-bound IL-15 in DCs was not addressed. However, we think it is plausible that treatment of DCs with both IFNs may have potentiated their capacity to transpresent IL-15 even in this setting. Indeed, IL-15 is really crucial in driving the activation and maintenance of memory CD8 T cells as shown in studies performed in the last decade $[61,63,65,66,112]$.

\subsection{IFN- $\alpha / \beta$ Can Upregulate an Important Costimulatory Molecule of DCs, CD70, Which Can Strongly Activate Lymphocytes by Binding to CD27}

More recently, we have found that another molecule induced by IFN- $\alpha$ in mouse DCs is CD70, the ligand for CD27 [113], a molecule very potent at stimulating T-cell responses, especially in the antitumor response settings $[113,114]$. Thus, we now know that CD70 expression and IL-15 transpresentation are both upregulated by IFN- $\alpha$ in mouse DCs [63]. This may represent another way by which IFN- $\alpha$ can potentiate DC activities and their capacity to activate the adaptive immune response, a pathway that deserves deeper analysis. What we have found recently is that IFN- $\alpha$-conditioned mouse DCs were able to increase homeostatic proliferation of memory CD8 T cells in vitro [63], with respect to untreated DCs, and this enhancer effect was indeed strongly dependent on both the increase of IL-15 transpresentation and CD70 stimulation [63] induced by IFN- $\alpha$. Interestingly, we have found that IFN- $\alpha$ alone is able to upregulate CD70 expression in human MDDCs as well (even at low doses, Frasca and Lande, 2010, unpublished observations), whereas Arimoto-Miyamoto et al. found that IFN- $\alpha$ could increase expression of this molecule on DCs stimulated by various stimuli, especially PGE2 [71]. Concomitantly, we have also asked whether IFN- $\gamma$ could do the same thing, and we found that it indeed induced CD70 expression on human DCs (Frasca and Lande, 2010, unpublished observation). Moreover, this effect is potentiated in combination with maturation stimuli, such as LPS.

Thus, the effect of IFN- $\gamma$ is again similar to that of type I IFN at stimulating CD70 upregulation. It is also known that IFN- $\gamma$, like IFN- $\alpha$, can upregulate IL-15 gene in DCs [61-64]. So we think that both type I and II IFNs can have multiple potentiating effects on both innate and adaptive immune responses also via regulation of these latter molecules on the DCs.

\subsection{IFN- $\alpha / \beta$, Similar to IFN- $\gamma$, Can Also Exert Some Inhibitory Effects on DC Functions}

In keeping with some inhibitory effects on DC functions of IFN- $\beta$ is the induction, by this IFN-type, of the inhibitory molecule B7-H1 (PD-L1) [49] that, as already mentioned, can be also induced by IFN- $\gamma$. Indeed, 
it has been suggested that another way by which IFN- $\beta$ can dampen inflammation in MS is the induction B7$\mathrm{H} 1$ on monocytes and DCs. IFN- $\beta$ was shown to enhance expression of this molecule on semimature DCs (for instance DCs treated with the sole TNF) suggesting that the state of activation of the DCs (and, therefore, their way of activation) may allow this molecule to exert a strong inhibitory effect on their production of proinflammatory factors and the consequent activation of CD4 T cells. Indeed, this molecular pathway has been shown to be crucial in the regulation of experimental autoimmune encephalomyelitis [115].

\subsection{IFN- $\alpha / \beta$, Like IFN- $\gamma$, Regulate DC Production of IL-27}

Another important issue has been the discovery of a link between type I IFN stimulation and IL-27 production by DCs. Even in this case type I IFNs seem to act similar to IFN- $\gamma[2,17,28]$. Coccia's group $[2,28]$ discovered that IFN- $\beta$ induces the p28 subunit of IL-27 [116] in MDDCs. This was evident whether IFN- $\beta$ was given exogenously or induced by LPS, by virtue of the activation of the autocrine IFN- $\beta$ loop. IL-27 expression was shown to depend on IRF-1. The authors proposed that secretion of IL-27 by IFN$\beta$-stimulated DCs could have a delayed anti-inflammatory effect on the immune response, as apposite to the activating effect due to the initial wave of IL-12p70 increase [28]. The autocrine loop leading to IFN- $\beta$ production by DCs is not always induced by all TLR stimulators [2]. In some cases, when a pathogen does not induce this loop in the DCs, exogenous provision of IFN- $\beta$ can enhance protective immune responses $[30,31]$. This implies that also IL-27 is not always produced by DCs, due to the lack of the same loop, with various consequences. An example of this is our study regarding the effects of different LPS, derived from different pathogenic bacteria [51], on human MDDC phenotype and functions. Unlike LPS from E. coli, which can induce the IFN- $\beta$ loop in maturing DCs and IL-27 [28, 51], the LPS derived from $B$. pertussis (called LOS) did not induce this loop and did not upregulate IL-27. As already mentioned, IL-27 is known to block Th-17 cells induction/expansions, and indeed LOS-stimulated MDDCs were able to expand Th-17 cells, unlikely the E. coli LPS-stimulated cells (which produced IL-27). Thus, lack of IL-27 production by the MDDCs favors Th-17 expansions. In this study responder T cells were not pure naïve cells. However, a subsequent study demonstrated a similar capacity of IL-27 released by the DCs to block induction of Th-17 cells using naïve T cells. Markovic-Plese's group demonstrated that IFN- $\beta 1$ treatment of DCs significantly inhibited the secretion of the Th-17-polarizing cytokines (IL-1 $\beta$, TGF- $\beta 1$, and IL-23) and induced the production of IL-27 [52]. They also showed that IFN- $\beta$ inhibits human Th-17 cell differentiation acting via the inhibition of the expression of $I L-1 \beta$ and $I L-23$, while inducing $I L-12 p 35$ and $I L-27 p 28$ in DCs derived from MS patients. DC supernatant transfer experiments confirmed that the IFN- $\beta$-1a-induced changes in DC cytokine secretion suppress the Th-17 markers RORc, IL-17A, and IL-23R. IFN- $\beta$-1a exhibited a direct effect on naive $\mathrm{CD}^{+}{ }^{+} \mathrm{CD} 45 \mathrm{RA}^{+} \mathrm{T}$ cells derived from both MS patients and healthy controls and inhibited their Th-17 differentiation, as evidenced by the inhibition of $R O R c, I L-17 A$, and $I L-23 R$ expression [53, 97]. It is tempting to speculate that different TLR stimulators derived by different pathogens can shape the response of DCs with respect to the IFN- $\beta$ loop and, by doing so, activate or not the Th-17-polarised response. For instance, TLR-2 stimulation, which inhibits the IFN- $\beta$ loop, induces DCs more prone to elicit Th-17 responses, while the opposite is true for TLR-4 stimulation [54].

Two interesting papers have demonstrated this mechanism of Th-17 inhibition mediated by type I in vivo, via DC modifications. These studies showed indeed that engagement of IFNAR blocks the severity of experimental autoimmune encephalomyelitis by inducing IL-27 by innate immune cells $[55,56]$. In particular, the DCs $[57,58]$ were shown to be the main targets of type I IFN effect, and their production of IL-27 prevented efficient Th-17 responses. Signaling triggered by type I IFN in DCs, leading to IL-27 production, was also found to be dependent on inhibition of OPN, which acts as a repressor of IL-27 expression. The same gene is inhibited in mouse DCs by IFN- $\gamma$ signaling (see above).

Thus, these recent researches have shown how type I IFN (as well as type II IFN) can affect the polarization of the adaptive immune response by acting via modification of the DCs, in this case by forcing these cells to produce a cytokine, IL-27, which dampens inflammation and concurs to block Th-17 generation, while also inhibiting other proinflammatory factors. 


\subsection{IFN- $\lambda$ : Also Called Type III IFNs}

Although not included in the type I or type II IFN family, a special mention in this paper deserves the type III IFNs, for their effects on DCs (partially overlapping with those of Type I IFNs) and because an internal loop of type III IFNs has also been discovered in DCs [2].

Type III IFNs are also known as IFN- $\lambda$, a family composed of three members such as IFN- $\lambda 1$ (IL-29), IFN- $\lambda 2$ (IL-28A), and IFN- $\lambda 3$ (IL-28B). IFN- $\lambda$ shared with type I IFNs an intracellular signaling pathway that drives the expression of a common set of genes. Indeed, the antiviral capacity of IFN- $\lambda$ is usually coexpressed with IFN- $\alpha / \beta$ released by virus-infected cells. However, IFN- $\lambda$ signaling is initiated through a membrane receptor system distinct from that of type I IFNs. IFN- $\lambda$ is recognized by a receptor formed of two chains, the specific receptor IFN- $\lambda \mathrm{R} 1$ and IL-10R $\beta$, that is recognized also by IL-10, IL-22, and IL-26. Blocking of IFN- $\alpha$ receptors does not inhibit signaling through IFN- $\lambda$, whereas inhibition of IFN- $\lambda$ receptors does not block IFN- $\alpha$ signaling indicating that both systems are activated independently [117].

Apart from viral stimulation, IFN- $\lambda$ is coexpressed with IFN- $\beta$ after TLR treatment in human DCs [2]. IFNs produced by DCs in response to TLR stimulation are critical in the differentiation and maturation of DCs, and DCs acquire IFN- $\lambda$ responsiveness through the expression of the specific receptor chains during their differentiation from monocytes. Even though IFN- $\lambda$ R 1 is abundantly expressed on the surface of epithelial cells and is weakly present on bone marrow cells and PBMCs, it has been shown that circulating immune cells are sensitive to IFN- $\lambda$. IFN- $\lambda$-treated DCs express high levels of MHC Class I and Class II molecules, but low levels of costimulatory molecules [118]. Mennechet and Uzé [119] published that IFN$\lambda$-treated DCs specifically induced IL-2-dependent proliferation of a CD $4^{+} \mathrm{CD} 25^{+}{ }^{\text {Foxp }} 3^{+}$T-cell subset with contact-dependent suppressive activity on T-cell proliferation initiated by fully mature DCs. IFN- $\lambda$ is, thus, able to generate "tolerogenic DCs," an activity that could thwart IFN- $\beta$ functions [2].

Interestingly, Coccia et al. have shown a differential expression of type I IFN and IFN- $\lambda$ genes by plasmacytoid DCs (pDCs) and MDDCs following viral infection or TLR ligand treatment. Indeed, pDCs coproduce large amount of type I and IFN- $\lambda$ irrespective of the type of stimulus (viruses or TLR agonists), whereas MDDCs coexpressed the two families of IFNs only when treated by viruses. On the other hand, MDDCs stimulated with TLR-3 or TLR-4 ligands release IFN- $\gamma$ and IFN- $\lambda$, but not IFN- $\alpha$.

Authors have published that even though type I IFNs and IFN- $\lambda$ are usually coexpressed by infected cells, IFN- $\alpha$ can amplify the induction of IFN- $\lambda$ by the Sendai or influenza viruses $[84,120]$.

\section{ADDITIVE AND COUNTERREGULATORY EFFCTS OF IFN- $\alpha / \beta$ AND $\gamma$ ON MYELOID DENDRITIC CELL FUNCTIONS}

As reviewed here, results reported in a wide literature show clearly that IFN- $\gamma$ shares some common mechanisms in the activation of the immune response with type I IFN. However, as previously mentioned, IFN- $\gamma$ appears more potent in some activities regarding enhancement of APC effector functions of DCs, as compared to type I IFN. Despite overlapping activities, in many works it has been shown that the two IFN types can have even opposite effects by counterregulating each other [121]. This effect has mainly been studied in T and NK cells [56] and was shown to depend on STAT1 induction in such cells by type I IFN. Indeed, type I IFN-induced STAT1 phosphorylation inhibited IFN- $\gamma$ production. However, all the interactions between type I and type II IFN-induced signals are complex, not completely elucidated, and may depend on the cell type analyzed $[57,58]$. It has also been postulated that the two IFN types share some common signaling factors [57], and in this way they regulate each other's effects, but other works do not support this view [58]. Low levels of endogenous type I IFN induced by TLR engagement during stimulation of DCs are reported to synergize with the NF- $\kappa$ B pathway for optimal IL-12p70 secretion [81], thus, indirectly contributing to IFN- $\gamma$ production (additive effects). Small quantities of type I IFN can "prime" cells to produce a robust response to type II IFN [57]. In the latter work such effect has been demonstrated in non-DC-type of cells. More recently, type I IFN has been demonstrated to prime IFN$\gamma$-mediated immune responses by regulating expression of STAT1 [58] in mouse embryonic fibroblasts. 
It will be interesting to know how similar loops are operative in DCs. When elevated concentrations are present, type I IFNs have been shown to act by suppressing IL-12p40 production, limiting the amount of the IL-12 heterodimers in another study [78]. Perhaps, the concentration of IFN- $\alpha / \beta$ is important in determining whether an enhancer of a counterregulatory effect will occur on the type II IFN responsiveness by the cells studied. However, this is not really known, and should be better clarified. Further focusing on DCs, it should be mentioned that, in some way, IFN- $\gamma$ seems to regulate the response to IFN- $\gamma$ itself in mature DCs. Indeed, it has been shown that reduced IL-12-producing capacity of mature DCs mainly results from their impaired responsiveness to IFN- $\gamma$, which, during the maturation process, is instead a cofactor in CD40-induced IL-12p70 production [21, 78, 81]. In the latter work, Kaliński et al. found that mature human DCs poorly responded to IFN- $\gamma$ administration, and this correlated with reduced expression of the IFNGR (CD119) [78, 81]. A similar phenomenon was noticed with respect to the IFN- $\alpha$ response. Even in this case, a reduction of the type I IFN receptor in maturing DCs, with progressive loss of response to this cytokine at final maturation, was reported [82]. As already mentioned, several studies showed that type I IFN enhances IL-12p70 production by immature DCs [73], an effect similar to that exerted by IFN- $\gamma$. However, it was shown that type I IFN, given during maturation, induced by IFN- $\gamma$ and CD40 ligation, counteracted the IL-12-enhancing effect of IFN- $\gamma$ on immature DCs. This is corroborated by findings that DCs matured in the presence of type I IFN usually respond with high IL-12p70 production upon subsequent CD40L stimulation, but only if, in the subsequent stimulation by CD40L, IFN- $\gamma$ was not present. Thus, in all these in vitro studies, it seems that type I IFN can modulate, in a negative fashion, the response of DCs to type II IFN.

The mechanisms responsible for cross-regulation of the IFN response in DCs are not completely elucidated. Competition for transcription factors shared by the two cytokines has been proposed in other cell types, or alteration of the phosphorylation status of STAT1, involved in signaling of both cytokines. However, the picture is more complicated. For instance, the already mentioned work by Kalinski's group showing that IFN- $\gamma$ and IFN- $\alpha$ can actually synergize in inducing human DC maturation and effector functions, seem in contrast with the observations reported above. IFN-induced functions are capacity to induce more effective cytotoxic T-cell stimulation and perform CCR7-driven migration, features that are crucial if human DCs need to be used in therapeutic protocols of adoptive transfer [24, 25]. However, one possible explanation for these contrasting results is that, in the Kalinsky's system, stimulation via CD40 triggering and/or TLR-induced activation of DCs is excluded, while only cytokine stimulation is performed [37]. Instead, when a physiological TLR stimulation is induced during an infection, the feedback loop between the two IFN types seems operative. Basically, type I IFN acting on DCs could work to prevent hyperactivation of the APCs and high IL-12p70 production in case that local IFN- $\gamma$ produced by bystander cells increases at too high levels. A similar mechanism has been demonstrated in vitro by two interesting papers. Rayamajhi et al. [122] found an antagonistic crosstalk between type I ad II IFN operative in vivo during L. monocytogenes infection. This infection induces type I IFN production, which in turn suppresses macrophage and DC activation by IFN- $\gamma$ by decreasing IFNGRI mRNA and IFN- $\gamma$ receptor surface expression on these APCs $[122,123]$. In this particular infectious model, production of sustained quantities of type I IFN during $L$. monocytogenes infection represents an escape strategy used by this bacterium to evade IFN- $\gamma$ responses that would be instead protective for the host. Obviously, IFNAR $-/-$ mice could resist $L$. monocytogenes, a phenomenon also evidenced in previous papers in different pathogenic bacterial infections [124-127]. MTB and Chlamydia trachomatis have also been found to suppress IFN- $\gamma$ responsiveness, and this escape $[83,128]$ may indeed involve counterregulation by type I and II IFNs. At the same time, such inhibitory crosstalk may explain why IFN- $\beta$ has a beneficial effect in MS, by dampening inflammation.

The second paper analyzing the counter-regulatory effects between IFNs in vivo is a study on inflammation induced by Pneumocystis $(P C)$ in CD4 T-cell competent mice. In this system, $P C$ infection of IFNR $\alpha \beta-/-$ hosts results in a chronicization of the disease and lung damage [129], revealing that in these settings type I IFN signaling is important to clear the infection and avoid the chronic disease. The authors showed that during $P C$ infection, production of type I IFN induces a regulatory loop involving upregulation of SOCS1 in CD11 ${ }^{+}$cells (namely, DCs, but also macrophages), which in turn prevents excessive IFN- $\gamma$ 
response. The latter response is the one that need to be taken under check because it is the key element determining lung damage. This is in keeping with another paper showing that lack of SOCS, particularly in DCs, led to a hyperinflammatory response in SOCS1-/- mice [130]. Thus, this is another way by which IFN- $\alpha$, by acting on the APC to upregulate SOCS1, can counterregulate IFN- $\gamma$ signaling in the APCs themselves, to limit uncontrolled inflammation.

\section{CONCLUDING REMARKS}

In this paper we have tried to point out the differences and similarities between the mechanisms of action of type II and I IFNs on myeloid DCs, a complicated field in which contrasting results have also been reported. Since these two IFN types are produced by many immune cells, the regulation of their expression, as well cell responsiveness to them in vivo can be very complicated to dissect. We have only tried to clarify the action of these two IFN types on one important immune cell that can have a big impact on both the innate and adaptive immune response. However, we would like to point out that in this picture, for lack of space, we did not address the important interactions of DCs with the cells that are the major producers of these IFN types. These cells are mainly represented by the NK cells (for review, see [131]), which are the most important source of IFN- $\gamma$ during the early phases of the immune response, and by pDCs, the main type I IFN producers. Like NK cells, pDCs are known to engage in a very important crosstalk with the myeloid DCs [85], an interplay that strongly involves type I IFN activity coupled with other important immune receptor triggering and soluble factor release (for review, see [80]).

\section{ACKNOWLEDGMENTS}

This work was partially supported by grant from the Ministry of Universities and Scientific and Technological Research (MIUR-COFIN).

\section{REFERENCES}

[1] M. K. Chelbi-Alix and J. Wietzerbin, "Interferon, a growing cytokine family: 50 years of interferon research," Biochimie, vol. 89, no. 6-7, pp. 713-718, 2007.

[2] E. M. Coccia, "IFN regulation and functions in myeloid dendritic cells," Cytokine and Growth Factor Reviews, vol. 19, no. 1, pp. 21-32, 2008.

[3] C. A. Bonjardim, P. C. P. Ferreira, and E. G. Kroon, "Interferons: signaling, antiviral and viral evasion," Immunology Letters, vol. 122, no. 1, pp. 1-11, 2009.

[4] O. H. Krämer and T. Heinzel, "Phosphorylation-acetylation switch in the regulation of STAT1 signaling," Molecular and Cellular Endocrinology, vol. 315, no. 1-2, pp. 40-48, 2009.

[5] X. Hu and L. B. Ivashkiv, "Cross-regulation of signaling pathways by interferon-gamma: implications for immune responses and autoimmune diseases," Immunity, vol. 31, no. 4, pp. 539-550, 2009.

[6] K. Schroder, M. J. Sweet, and D. A. Hume, "Signal integration between IFN $\gamma$ and TLR signalling pathways in macrophages," Immunobiology, vol. 211, no. 6-8, pp. 511-524, 2006.

[7] L. C. Platanias, "Mechanisms of type-I- and type-II-interferon-mediated signalling," Nature Reviews Immunology, vol. 5, no. 5, pp. 375-386, 2005.

[8] A. Billiau and P. Matthys, "Interferon- $\gamma$ : a historical perspective," Cytokine and Growth Factor Reviews, vol. 20, no. 2, pp. 97-113, 2009.

[9] R. Reljic, "IFN- $\gamma$ therapy of tuberculosis and related infections," Journal of Interferon and Cytokine Research, vol. 27, no. 5, pp. 353-364, 2007.

[10] J. Zhang, "Yin and yang interplay of IFN $-\gamma$ in inflammation and autoimmune disease," Journal of Clinical Investigation, vol. 117, no. 4, pp. 871-873, 2007.

[11] H. Kelchtermans, A. Billiau, and P. Matthys, "How interferon- $\gamma$ keeps autoimmune diseases in check," Trends in Immunology, vol. 29, no. 10, pp. 479-486, 2008. 
[12] L. Flaishon, R. Hershkoviz, F. Lantner et al., "Autocrine secretion of interferon $\gamma$ negatively regulates homing of immature B cells,” Journal of Experimental Medicine, vol. 192, no. 9, pp. 1381-1387, 2000.

[13] Y. Refaeli, L. Van Parijs, S. I. Alexander, and A. K. Abbas, "Interferon $\gamma$ is required for activation-induced death of T lymphocytes," Journal of Experimental Medicine, vol. 196, no. 7, pp. 999-1005, 2002.

[14] Z. Wang, J. Hong, W. Sun et al., "Role of IFN- $\gamma$ in induction of Foxp3 and conversion of CD4 ${ }^{+}$CD25 $5^{-}$T cells to CD4 ${ }^{+}$Tregs," Journal of Clinical Investigation, vol. 116, no. 9, pp. 2434-2441, 2006.

[15] L. E. Harrington, R. D. Hatton, P. R. Mangan et al., "Interleukin 17-producing CD4 ${ }^{+}$effector T cells develop via a lineage distinct from the T helper type 1 and 2 lineages," Nature Immunology, vol. 6, no. 11, pp. 1123-1132, 2005.

[16] E. Bettelli, M. Oukka, and V. K. Kuchroo, "TH-17 cells in the circle of immunity and autoimmunity," Nature Immunology, vol. 8, no. 4, pp. 345-350, 2007.

[17] L. Frasca, M. Nasso, F. Spensieri et al., "IFN- $\gamma$ arms human dendritic cells to perform multiple effector functions," Journal of Immunology, vol. 180, no. 3, pp. 1471-1481, 2008.

[18] A. N. Theofilopoulos, R. Baccala, B. Beutler, and D. H. Kono, "Type I interferons $(\alpha / \beta)$ in immunity and autoimmunity," Annual Review of Immunology, vol. 23, pp. 307-336, 2005.

[19] M. Prinz and U. Kalinke, "New lessons about old molecules: how type I interferons shape Th1/Th17-mediated autoimmunity in the CNS," Trends in Molecular Medicine, vol. 16, no. 8, pp. 379-386, 2010.

[20] G. Trinchieri, “Type I interferon: friend or foe?” Journal of Experimental Medicine, vol. 207, no. 10, pp. 20532063, 2010.

[21] G. M. Keating, "Peginterferon- $\alpha-2 \mathrm{a}(40 \mathrm{kD})$ : a review of its use in chronic hepatitis B," Drugs, vol. 69, no. 18, pp. 2633-2660, 2009.

[22] S. Zhao, E. Liu, P. Chen et al., "A comparison of peginterferon $\alpha-2 \mathrm{a}$ and $\alpha-2 \mathrm{~b}$ for treatment-naive patients with chronic hepatitis C virus: a meta-analysis of randomized trials," Clinical Therapeutics, vol. 32, no. 9, pp. 1565-1577, 2010.

[23] P. Rizza, F. Moretti, and F. Belardelli, "Recent advances on the immunomodulatory effects of IFN- $\alpha$ : implications for cancer immunotherapy and autoimmunity," Autoimmunity, vol. 43, no. 3, pp. 204-209, 2010.

[24] P. Kalinski and H. Okada, "Polarized dendritic cells as cancer vaccines: directing effector-type T cells to tumors," Seminars in Immunology, vol. 22, no. 3, pp. 173-182, 2010.

[25] P. Kalinski, "Dendritic cells in immunotherapy of established cancer: roles of signals 1, 2, 3 and 4," Current Opinion in Investigational Drugs, vol. 10, no. 6, pp. 526-535, 2009.

[26] A. Snijders, P. Kalinski, C. M. U. Hilkens, and M. L. Kapsenberg, "High-level IL-12 production by human dendritic cells requires two signals," International Immunology, vol. 10, no. 11, pp. 1593-1598, 1998.

[27] P. J. Mosca, A. C. Hobeika, T. M. Clay et al., "A subset of human monocyte-derived dendritic cells expresses high levels of interleukin-12 in response to combined CD40 ligand and interferon- $\gamma$ treatment," Blood, vol. 96, no. 10, pp. 3499-3504, 2000.

[28] M. E. Remoli, V. Gafa, E. Giacomini, M. Severa, R. Lande, and E. M. Coccia, "IFN- $\beta$ modulates the response to TLR stimulation in human DC: involvement of IFN regulatory factor-1 (IRF-1) in IL-27 gene expression," European Journal of Immunology, vol. 37, no. 12, pp. 3499-3508, 2007.

[29] T. Nagai, O. Devergne, T. F. Mueller, D. L. Perkins, J. M. Van Seventer, and G. A. Van Seventer, "Timing of IFN-beta exposure during human dendritic cell maturation and naive Th cell stimulation has contrasting effects on Th1 subset generation: a role for IFN-beta-mediated regulation of IL-12 family cytokines and IL-18 in naive Th cell differentiation," Journal of Immunology, vol. 171, no. 10, pp. 5233-5243, 2003.

[30] E. Giacomini, M. E. Remoli, V. Gafa, M. Pardini, L. Fattorini, and E. M. Coccia, "IFN- $\beta$ improves BCG immunogenicity by acting on DC maturation," Journal of Leukocyte Biology, vol. 85, no. 3, pp. 462-468, 2009.

[31] V. Gafa, M. E. Remoli, E. Giacomini, M. Severa, R. Grillot, and E. M. Coccia, "Enhancement of anti-aspergillus T helper type 1 response by interferon- $\beta$-conditioned dendritic cells," Immunology, vol. 131, no. 2, pp. 282-288, 2010.

[32] T. Luft, P. Luetjens, H. Hochrein et al., "IFN- $\alpha$ enhances CD40 ligand-mediated activation of immature monocyte-derived dendritic cells," International Immunology, vol. 14, no. 4, pp. 367-380, 2002.

[33] R. Lemoine, F. Velge-Roussel, F. Herr et al., "Interferon gamma licensing of human dendritic cells in T-helperindependent CD8+ alloimmunity," Blood, vol. 116, no. 16, pp. 3089-3098, 2010. 
[34] J. H. Yen, W. Kong, and D. Ganea, "IFN- $\beta$ inhibits dendritic cell migration through STAT-1-mediated transcriptional suppression of CCR7 and matrix metalloproteinase 9," Journal of Immunology, vol. 184, no. 7, pp. 3478-3486, 2010.

[35] P. L. Vieira, E. C. de Jong, E. A. Wierenga, M. L. Kapsenberg, and P. Kaliński, "Development of Th1-inducing capacity in myeloid dendritic cells requires environmental instruction," Journal of Immunology, vol. 164, no. 9, pp. 4507-4512, 2000.

[36] S. Parlato, S. M. Santini, C. Lapenta et al., "Expression of CCR-7, MIP-3 $\beta$, and Th-1 chemokines in type I IFN-induced monocyte-derived dendritic cells: importance for the rapid acquisition of potent migratory and functional activities," Blood, vol. 98, no. 10, pp. 3022-3029, 2001.

[37] R. B. Mailliard, A. Wankowicz-Kalinska, Q. Cai et al., " $\alpha$-type-1 polarized dendritic cells: a novel immunization tool with optimized CTL-inducing activity," Cancer Research, vol. 64, no. 17, pp. 5934-5937, 2004.

[38] G. Fedele, L. Frasca, R. Palazzo, E. Ferrero, F. Malavasi, and C. M. Ausiello, "CD38 is expressed on human mature monocyte-derived dendritic cells and is functionally involved in CD83 expressioin and IL-12 induction," European Journal of Immunology, vol. 34, no. 5, pp. 1342-1350, 2004.

[39] L. Frasca, G. Fedele, S. Deaglio et al., "CD38 orchestrates migration, survival, and Th1 immune response of human mature dendritic cells," Blood, vol. 107, no. 6, pp. 2392-2399, 2006.

[40] P. Hartiala, J. Hytönen, H. Yrjänäinen et al., "TLR2 utilization of Borrelia does not induce p38- and IFN- $\beta$ autocrine loop-dependent expression of CD38, resulting in poor migration and weak IL-12 secretion of dendritic cells," Journal of Immunology, vol. 184, no. 10, pp. 5732-5742, 2010.

[41] M. C. Lebre, T. Burwell, P. L. Vieira et al., "Differential expression of inflammatory chemokines by Th1- and Th2-cell promoting dendritic cells: a role for different mature dendritic cell populations in attracting appropriate effector cells to peripheral sites of inflammation," Immunology and Cell Biology, vol. 83, no. 5, pp. 525-535, 2005.

[42] E. Padovan, G. C. Spagnoli, M. Ferrantini, and M. Heberer, "IFN- $\alpha 2$ a induces IP-10/CXCL10 and MIG/CXCL9 production in monocyte-derived dendritic cells and enhances their capacity to attract and stimulate CD8+ effector T cells," Journal of Leukocyte Biology, vol. 71, no. 4, pp. 669-676, 2002.

[43] R. Lande, E. Giacomini, T. Grassi et al., "IFN- $\alpha \beta$ released by Mycobacterium tuberculosis-infected human dendritic cells induces the expression of CXCL10: selective recruitment of NK and activated T cells," Journal of Immunology, vol. 170, no. 3, pp. 1174-1182, 2003.

[44] D. Rojas and R. Krishnan, "IFN- $\gamma$ generates maturation-arrested dendritic cells that induce T cell hyporesponsiveness independent of Foxp3+ T-regulatory cell generation," Immunology Letters, vol. 132, no. 1-2, pp. 31-37, 2010.

[45] A. Eljaafari, Y. P. Li, and P. Miossec, "IFN- $\gamma$, as secreted during an alloresponse, induces differentiation of monocytes into tolerogenic dendritic cells, resulting in FoxP3+ regulatory T cell promotion," Journal of Iтmиnology, vol. 183, no. 5, pp. 2932-2945, 2009.

[46] M. Shinomiya, S. M. Fazle Akbar, H. Shinomiya, and M. Onji, "Transfer of dendritic cells (DC) ex vivo stimulated with interferon- gamma (IFN- $\gamma$ ) down-modulates autoimmune diabetes in non-obese diabetic (nod) mice," Clinical and Experimental Immunology, vol. 117, no. 1, pp. 38-43, 1999.

[47] S. B. Adikari, H. Lian, H. Link, Y. M. Huang, and B. G. Xiao, "Interferon- $\gamma$-modified dendritic cells suppress B cell function and ameliorate the development of experimental autoimmune myasthenia gravis," Clinical and Experimental Immunology, vol. 138, no. 2, pp. 230-236, 2004.

[48] G. J. Freeman, A. J. Long, Y. Iwai et al., "Engagement of the PD-1 immunoinhibitory receptor by a novel B7 family member leads to negative regulation of lymphocyte activation," Journal of Experimental Medicine, vol. 192, no. 7, pp. 1027-1034, 2000.

[49] B. Schreiner, M. Mitsdoerffer, B. C. Kieseier et al., "Interferon- $\beta$ enhances monocyte and dendritic cell expression of B7-H1 (PD-L1), a strong inhibitor of autologous T-cell activation: relevance for the immune modulatory effect in multiple sclerosis," Journal of Neuroimmunology, vol. 155, no. 1-2, pp. 172-182, 2004.

[50] G. Murugaiyan, A. Mittal, and H. L. Weiner, "Identification of an IL-27/osteopontin axis in dendritic cells and its modulation by IFN- $\gamma$ limits IL-17-mediated autoimmune inflammation," Proceedings of the National Academy of Sciences of the United States of America, vol. 107, no. 25, pp. 11495-11500, 2010.

[51] G. Fedele, M. Nasso, F. Spensieri et al., "Lipopolysaccharides from bordetella pertussis and bordetella parapertussis differently modulate human dendritic cell functions resulting in divergent prevalence of Th117polarized responses," Journal of Immunology, vol. 181, no. 1, pp. 208-216, 2008. 
[52] X. Zhang, J. Jin, Y. Tang, D. Speer, D. Sujkowska, and S. Markovic-Plese, "IFN- $\beta$ 1a inhibits the secretion of Th17-polarizing cytokines in human dendritic cells via TLR7 up-regulation," Journal of Immunology, vol. 182, no. 6, pp. 3928-3936, 2009.

[53] X. Zhang and S. Markovic-Plese, "Interferon beta inhibits the Th17 cell-mediated autoimmune response in patients with relapsing-remitting multiple sclerosis," Clinical Neurology and Neurosurgery, vol. 112, no. 7, pp. 641-645, 2010.

[54] M. H. Wenink, K. C. M. Santegoets, J. C. A. Broen et al., "TLR2 promotes Th2/Th17 responses via TLR4 and TLR7/8 by abrogating the type I IFN amplification loop," Journal of Immunology, vol. 183, no. 11, pp. 6960-6970, 2009.

[55] B. Guo, E. Y. Chang, and G. Cheng, "The type I IFN induction pathway constrains Th17-mediated autoimmune inflammation in mice," Journal of Clinical Investigation, vol. 118, no. 5, pp. 1680-1690, 2008.

[56] M. L. Shinohara, J. H. Kim, V. A. Garcia, and H. Cantor, "Engagement of the type I interferon receptor on dendritic cells inhibits T helper 17 cell development: role of intracellular osteopontin," Immunity, vol. 29, no. 1, pp. 68-78, 2008.

[57] A. Takaoka, Y. Mitani, H. Suemori et al., "Cross talk between interferon- $\gamma$ and $-\alpha / \beta$ signaling components in caveolar membrane domains," Science, vol. 288, no. 5475, pp. 2357-2360, 2000.

[58] D. J. Gough, N. L. Messina, L. Hii et al., "Functional crosstalk between type I and II interferon through the regulated expression of STAT1," PLoS Biology, vol. 8, no. 4, 2010.

[59] F. Zhou, "Molecular mechanisms of IFN- $\gamma$ to up-regulate MHC class i antigen processing and presentation," International Reviews of Immunology, vol. 28, no. 3-4, pp. 239-260, 2009.

[60] M. Jinushi, T. Takehara, T. Kanto et al., "Critical role of MHC class I-related chain A and B expression on IFN$\alpha$-stimulated dendritic cells in NK cell activation: impairment in chronic hepatitis C virus infection," Journal of Immunology, vol. 170, no. 3, pp. 1249-1256, 2003.

[61] A. G. Sikora, N. Jaffarzad, Y. Hailemichael et al., "IFN- $\alpha$ enhances peptide vaccine-induced CD8+ T cell numbers, effector function, and antitumor activity," Journal of Immunology, vol. 182, no. 12, pp. 7398-7407, 2009.

[62] J. E. Boudreau, K. B. Stephenson, F. Wang et al., "IL-15 and type I interferon are required for activation of tumoricidal NK cells by virus-infected dendritic cells," Cancer Research, vol. 71, no. 7, pp. 2497-2506, 2011.

[63] L. Frasca, S. W. Stonier, W. W. Overwijk, and K. S. Schluns, "Differential mechanisms of memory CD8 T cell maintenance by individual myeloid cell types," Journal of Leukocyte Biology, vol. 88, no. 1, pp. 69-78, 2010.

[64] B. Morandi, L. Mortara, P. Carrega et al., "NK cells provide helper signal for CD8+ T cells by inducing the expression of membrane-bound IL-15 on DCs," International Immunology, vol. 21, no. 5, pp. 599-606, 2009.

[65] V. Budagian, E. Bulanova, R. Paus, and S. Bulfone-Paus, "IL-15/IL-15 receptor biology: a guided tour through an expanding universe," Cytokine and Growth Factor Reviews, vol. 17, no. 4, pp. 259-280, 2006.

[66] S. W. Stonier and K. S. Schluns, "Trans-presentation: a novel mechanism regulating IL-15 delivery and responses," Immunology Letters, vol. 127, no. 2, pp. 85-92, 2010.

[67] F. Mattei, G. Schiavoni, F. Belardelli, and D. F. Tough, "IL-15 is expressed by dendritic cells in response to type I IFN, double-stranded RNA, or lipopolysaccharide and promotes dendritic cell activation," Journal of Immunology, vol. 167, no. 3, pp. 1179-1187, 2001.

[68] M. Jinushi, T. Takehara, T. Tatsumi et al., "Autocrine/Paracrine IL-15 That Is Required for Type I IFN-Mediated Dendritic Cell Expression of MHC Class I-Related Chain A and B Is Impaired in Hepatitis C Virus Infection," Journal of Immunology, vol. 171, no. 10, pp. 5423-5429, 2003.

[69] M. Lucas, W. Schachterle, K. Oberle, P. Aichele, and A. Diefenbach, "Dendritic cells prime natural killer cells by trans-presenting interleukin 15," Immunity, vol. 26, no. 4, pp. 503-517, 2007.

[70] E. Mortier, T. Woo, R. Advincula, S. Gozalo, and A. Ma, "IL-15R $\alpha$ chaperones IL-15 to stable dendritic cell membrane complexes that activate NK cells via trans presentation," Journal of Experimental Medicine, vol. 205, no. 5, pp. 1213-1225, 2008.

[71] K. Arimoto-Miyamoto, N. Kadowaki, T. Kitawaki, S. Iwata, C. Morimoto, and T. Uchiyama, "Optimal stimulation for CD70 induction on human monocyte-derived dendritic cells and the importance of CD70 in naive CD4 ${ }^{+}$T-cell differentiation," Immunology, vol. 130, no. 1, pp. 137-149, 2010.

[72] L. Ma, C. Mauro, G. H. Cornish et al., "Ig gene-like molecule CD31 plays a nonredundant role in the regulation of T-cell immunity and tolerance," Proceedings of the National Academy of Sciences of the United States of America, vol. 107, no. 45, pp. 19461-19466, 2010. 
[73] H. C. Heystek, B. den Drijver, M. L. Kapsenberg, R. A. W. van Lier, and E. C. de Jong, "Type I IFNs differentially modulate IL-12p70 production by human dendritic cells depending on the maturation status of the cells and counteract IFN- $\gamma$-mediated signaling," Clinical Immunology, vol. 107, no. 3, pp. 170-177, 2003.

[74] R. Rajaiah, M. Puttabyatappa, S. K. Polumuri, and K. D. Moudgil, "Interleukin-27 and interferon- $\gamma$ are involved in regulation of autoimmune arthritis," The Journal of Biological Chemistry, vol. 286, no. 4, pp. 2817-2825, 2011.

[75] S. L. Masters, L. A. Mielke, A. L. Cornish et al., "Regulation of interleukin- $1 \beta$ by interferon- $\gamma$ is species specific, limited by suppressor of cytokine signalling 1 and influences interleukin-17 production," EMBO Reports, vol. 11, no. 8, pp. 640-646, 2010.

[76] A. A. Byrnes, M. Xiaojing, P. Cuomo et al., "Type I interferons and IL-12: convergence and cross-regulation among mediators of cellular immunity," European Journal of Immunology, vol. 31, no. 7, pp. 2026-2034, 2001.

[77] G. Gautier, M. Humbert, F. Deauvieau et al., "A type I interferon autocrine-paracrine loop is involved in Tolllike receptor-induced interleukin-12p70 secretion by dendritic cells," Journal of Experimental Medicine, vol. 201, no. 9, pp. 1435-1446, 2005.

[78] P. Kaliński, J. H. N. Schuitemaker, C. M. U. Hilkens, E. A. Wierenga, and M. L. Kapsenberg, "Final maturation of dendritic cells is associated with impaired responsiveness to IFN- $\gamma$ and to bacterial IL-12 inducers: decreased ability of mature dendritic cells to produce IL-12 during the interaction with Th cells," Journal of Immunology, vol. 162, no. 6, pp. 3231-3236, 1999.

[79] B. L. McRae, B. A. Beilfuss, and G. A. van Seventer, "IFN- $\beta$ differentially regulates CD40-induced cytokine secretion by human dendritic cells," Journal of Immunology, vol. 164, no. 1, pp. 23-28, 2000.

[80] B. Pulendran, H. Tang, and T. L. Denning, "Division of labor, plasticity, and crosstalk between dendritic cell subsets," Current Opinion in Immunology, vol. 20, no. 1, pp. 61-67, 2008.

[81] R. B. Mailliard, S. Egawa, Q. Cai et al., "Complementary dendritic cell-activating function of CD8+ and CD4+ T cells: helper role of CD8+ T cells in the development of T helper type responses," Journal of Experimental Medicine, vol. 195, no. 4, pp. 473-483, 2002.

[82] M. C. Gauzzi, I. Canini, P. Eid, F. Belardelli, and S. Gessani, "Loss of type I IFN receptors and impaired IFN responsiveness during terminal maturation of monocyte-derived human dendritic cells," Journal of Immunology, vol. 169, no. 6, pp. 3038-3045, 2002.

[83] R. J. Belland, D. E. Nelson, D. Virok et al., "Transcriptome analysis of chlamydial growth during IFN- $\gamma$ mediated persistence and reactivation," Proceedings of the National Academy of Sciences of the United States of America, vol. 100, no. 26, pp. 15971-15976, 2003.

[84] P. Österlund, V. Veckman, J. Sirén et al., "Gene expression and antiviral activity of alpha/beta interferons and interleukin-29 in virus-infected human myeloid dendritic cells," Journal of Virology, vol. 79, no. 15, pp. 96089617, 2005.

[85] N. Kadowaki, "The divergence and interplay between pDC and mDC in humans," Frontiers in Bioscience, vol. 14, no. 3, pp. 808-817, 2009.

[86] F. Moschella, E. Proietti, I. Capone, and F. Belardelli, "Combination strategies for enhancing the efficacy of immunotherapy in cancer patients," Annals of the New York Academy of Sciences, vol. 1194, pp. 169-178, 2010.

[87] M. S. Ola, M. Nawaz, and H. Ahsan, "Role of Bcl-2 family proteins and caspases in the regulation of apoptosis," Molecular and Cellular Biochemistry, vol. 351, no. 1-2, pp. 41-58, 2011.

[88] P. J. Murray, "Understanding and exploiting the endogenous interleukin-10/STAT3-mediated anti-inflammatory response," Current Opinion in Pharmacology, vol. 6, no. 4, pp. 379-386, 2006.

[89] F. Cheng, H. W. Wang, A. Cuenca et al., "A critical role for Stat3 signaling in immune tolerance," Immunity, vol. 19, no. 3, pp. 425-436, 2003.

[90] Y. Nefedova, P. Cheng, D. Gilkes et al., "Activation of dendritic cells via inhibition of Jak2/STAT3 signaling," Journal of Immunology, vol. 175, no. 7, pp. 4338-4346, 2005.

[91] N. Sánchez-Sánchez, L. Riol-Blanco, and J. L. Rodríguez-Fernández, "The multiple personalities of the chemokine receptor CCR7 in dendritic cells," Journal of Immunology, vol. 176, no. 9, pp. 5153-5159, 2006.

[92] J. Alder, M. Hahn-Zoric, B. A. Andersson, and A. Karlsson-Parra, "Interferon- $\gamma$ dose-dependently inhibits prostaglandin E2-mediated dendritic-cell-migration towards secondary lymphoid organ chemokines," Vaccine, vol. 24, no. 49-50, pp. 7087-7094, 2006. 
[93] U. Dianzani, A. Funaro, D. DiFranco et al., "Interaction between endothelium and CD4 ${ }^{+}$CD45RA ${ }^{+}$lymphocytes: role of the human CD38 molecule," Journal of Immunology, vol. 153, no. 3, pp. 952-959, 1994.

[94] C. Pot, L. Apetoh, A. Awasthi, and V. K. Kuchroo, "Molecular pathways in the induction of interleukin-27driven regulatory type 1 cells," Journal of Interferon \& Cytokine Research, vol. 30, no. 6, pp. 381-388, 2010.

[95] D. T. Denhardt, M. Noda, A. W. O'Regan, D. Pavlin, and J. S. Berman, "Osteopontin as a means to cope with environmental insults: regulation of inflammation, tissue remodeling, and cell survival," Journal of Clinical Investigation, vol. 107, no. 9, pp. 1055-1061, 2001.

[96] G. Murugaiyan, A. Mittal, and H. L. Weiner, "Increased osteopontin expression in dendritic cells amplifies IL-17 production by CD4+ T cells in experimental autoimmune encephalomyelitis and in multiple sclerosis," Journal of Immunology, vol. 181, no. 11, pp. 7480-7488, 2008.

[97] V. S. Ramgolam, Y. Sha, J. Jin, X. Zhang, and S. Markovic-Plese, "IFN- $\beta$ inhibits human Th17 cell differentiation," Journal of Immunology, vol. 183, no. 8, pp. 5418-5427, 2009.

[98] A. L. Mellor and D. H. Munn, "IDO expression by dendritic cells: tolerance and tryptophan catabolism," Nature Reviews Immunology, vol. 4, no. 10, pp. 762-774, 2004.

[99] B. Jürgens, U. Hainz, D. Fuchs, T. Felzmann, and A. Heitger, "Interferon- $\gamma$-triggered indoleamine 2,3-dioxygenase competence in human monocyte-derived dendritic cells induces regulatory activity in allogeneic T cells," Blood, vol. 114, no. 15, pp. 3235-3243, 2009.

[100] M. J. Fenton, M. W. Vermeulen, S. Kim, M. Burdick, R. M. Strieter, and H. Kornfeld, "Induction of gamma interferon production in human alveolar macrophages by Mycobacterium tuberculosis," Infection and Immunity, vol. 65, no. 12, pp. 5149-5156, 1997.

[101] D. Stober, R. Schirmbeck, and J. Reimann, "IL-12/IL-18-dependent IFN- $\gamma$ release by murine dendritic cells," Journal of Immunology, vol. 167, no. 2, pp. 957-965, 2001.

[102] D. M. Frucht, T. Fukao, C. Bogdan, H. Schindler, J. J. O’Shea, and S. Koyasu, "IFN- $\gamma$ production by antigenpresenting cells: mechanisms emerge," Trends in Immunology, vol. 22, no. 10, pp. 556-560, 2001.

[103] K. Suzue, T. Asai, T. Takeuchi, and S. Koyasu, "In vivo role of IFN- $\gamma$ produced by antigen-presenting cells in early host defense against intracellular pathogens," European Journal of Immunology, vol. 33, no. 10, pp. 2666-2675, 2003.

[104] G. Lugo-Villarino, R. Maldonado-López, R. Possemato, C. Peñaranda, and L. H. Glimcher, "T-bet is required for optimal production of IFN- $\gamma$ and antigen-specific T cell activation by dendritic cells," Proceedings of the National Academy of Sciences of the United States of America, vol. 100, no. 13, pp. 7749-7754, 2003.

[105] A. A. Lighvani, D. M. Frucht, D. Jankovic et al., "T-bet is rapidly induced by interferon- $\gamma$ in lymphoid and myeloid cells," Proceedings of the National Academy of Sciences of the United States of America, vol. 98, no. 26, pp. 15137-15142, 2001.

[106] I. Fricke, D. Mitchell, J. Mittelstädt et al., "Mycobacteria induce IFN- $\gamma$ production in human dendritic cells via triggering of TLR2," Journal of Immunology, vol. 176, no. 9, pp. 5173-5182, 2006.

[107] Y. Iwai, H. Hemmi, O. Mizenina, S. Kuroda, K. Suda, and R. M. Steinman, "An IFN- $\gamma$-IL-18 signaling loop accelerates memory CD8+ T cell proliferation," PLOS ONE, vol. 3, no. 6, Article ID e2404, 2008.

[108] H. Li, W. Wojciechowski, C. Dell'Agnola, N. E. Lopez, and I. Espinoza-Delgado, "IFN- $\gamma$ and T-bet expression in human dendritic cells from normal donors and cancer patients is controlled through mechanisms involving ERK-1/2-dependent and IL-12-independent pathways," Journal of Immunology, vol. 177, no. 6, pp. 3554-3563, 2006.

[109] E. M. Coccia, M. Severa, E. Giacomini et al., "Viral infection and toll-like receptor agonists induce a differential expression of type I and $\lambda$ interferons in humans plasmacytoid and monocyte-derived dendritic cells," European Journal of Immunology, vol. 34, no. 3, pp. 796-805, 2004.

[110] R. Trepiakas, A. E. Pedersen, Ö. Met, and I. M. Svane, "Addition of interferon-alpha to a standard maturation cocktail induces CD38 up-regulation and increases dendritic cell function," Vaccine, vol. 27, no. 16, pp. $2213-$ 2219, 2009.

[111] E. F. Castillo, S. W. Stonier, L. Frasca, and K. S. Schluns, "Dendritic cells support the in vivo development and maintenance of NK cells via IL-15 trans-presentation," Journal of Immunology, vol. 183, no. 8, pp. 4948-4956, 2009.

[112] S. W. Stonier, L. J. Ma, E. F. Castillo, and K. S. Schluns, "Dendritic cells drive memory CD8 T-cell homeostasis via IL-15 transpresentation," Blood, vol. 112, no. 12, pp. 4546-4554, 2008. 
[113] J. Borst, J. Hendriks, and Y. Xiao, "CD27 and CD70 in T cell and B cell activation," Current Opinion in Immunology, vol. 17, no. 3, pp. 275-281, 2005.

[114] T. E. Boursalian, J. A. McEarchern, C. L. Law, and I. S. Grewal, "Targeting CD70 for human therapeutic use," Advances in Experimental Medicine and Biology, vol. 647, pp. 108-119, 2009.

[115] A. D. Salama, T. Chitnis, J. Imitola et al., "Critical role of the programmed death-1 (PD-1) pathway in regulation of experimental autoimmune encephalomyelitis," Journal of Experimental Medicine, vol. 198, no. 1, pp. 71-78, 2003

[116] H. Yoshida and M. Yoshiyuki, "Regulation of immune responses by interleukin-27," Immunological Reviews, vol. 226, no. 1, pp. 234-247, 2008.

[117] R. P. Donnelly and S. V. Kotenko, "Interferon-lambda: a new addition to an old family," Journal of Interferon and Cytokine Research, vol. 30, no. 8, pp. 555-564, 2010.

[118] S. V. Kotenko, G. Gallagher, V. V. Baurin et al., "IFN- $\lambda$ s mediate antiviral protection through a distinct class II cytokine receptor complex," Nature Immunology, vol. 4, no. 1, pp. 69-77, 2003.

[119] F. J. D. Mennechet and G. Uzé, "Interferon- $\lambda$-treated dendritic cells specifically induce proliferation of FOXP3expressing suppressor T cells," Blood, vol. 107, no. 11, pp. 4417-4423, 2006.

[120] J. Sirén, J. Pirhonen, I. Julkunen, and S. Matikainen, "IFN- $\alpha$ regulates TLR-dependent gene expression of IFN$\alpha$, IFN- $\beta$, IL-28, and IL-29," Journal of Immunology, vol. 174, no. 4, pp. 1932-1937, 2005.

[121] K. B. Nguyen, L. P. Cousens, L. A. Doughty, G. C. Pien, J. E. Durbin, and C. A. Biron, "Interferon $\alpha / \beta-$ mediated inhibition and promotion of interferon $\gamma$ : STAT1 resolves a paradox," Nature Immunology, vol. 1, no. 1, pp. 70-76, 2000.

[122] M. Rayamajhi, J. Humann, K. Penheiter, K. Andreasen, and L. L. Lenz, "Induction of IFN- $\alpha \beta$ enables Listeria monocytogenes to suppress macrophage activation by IFN- $\gamma$," Journal of Experimental Medicine, vol. 207, no. 2, pp. 327-337, 2010.

[123] M. Rayamajhi, J. Humann, S. Kearney, K. K. Hill, and L. L. Lenz, "Antagonistic crosstalk between type I and II interferons and increased host susceptibility to bacterial infections," Virulence, vol. 1, no. 5, pp. 418-422, 2010.

[124] S. A. Stanley, J. E. Johndrow, P. Manzanillo, and J. S. Cox, "The type I IFN response to infection with Mycobacterium tuberculosis requires ESX-1-mediated secretion and contributes to pathogenesis," Journal of Immunology, vol. 178, no. 5, pp. 3143-3152, 2007.

[125] H. Qiu, Y. Fan, A. G. Joyee et al., "Type I IFNs enhance susceptibility to Chlamydia muridarum lung infection by enhancing apoptosis of local macrophages," Journal of Immunology, vol. 181, no. 3, pp. 2092-2102, 2008.

[126] F. J. Martin, M. I. Gomez, D. M. Wetzel et al., "Staphylococcus aureus activates type I IFN signaling in mice and humans through the Xr repeated sequences of protein A," Journal of Clinical Investigation, vol. 119, no. 7, pp. 1931-1939, 2009.

[127] A. Shahangian, E. K. Chow, X. Tian et al., "Type I IFNs mediate development of postinfluenza bacterial pneumonia in mice," Journal of Clinical Investigation, vol. 119, no. 7, pp. 1910-1920, 2009.

[128] E. Z. Kincaid and J. D. Ernst, "Mycobacterium tuberculosis exerts gene-selective inhibition of transcriptional responses to IFN- $\gamma$ without inhibiting STAT1 function," Journal of Immunology, vol. 171, no. 4, pp. 2042-2049, 2003.

[129] N. Meissner, S. Swain, K. McInnerney, S. Han, and A. G. Harmsen, "Type-I IFN signaling suppresses an excessive IFN- $\gamma$ response and thus prevents lung damage and chronic inflammation during Pneumocystis (PC) clearance in CD4 T cell-competent mice," American Journal of Pathology, vol. 176, no. 6, pp. 2806-2818, 2010.

[130] T. Hanada, H. Yoshida, S. Kato et al., "Suppressor of cytokine signaling-1 is essential for suppressing dendritic cell activation and systemic autoimmunity," Immunity, vol. 19, no. 3, pp. 437-450, 2003.

[131] L. Moretta, G. Ferlazzo, C. Bottino et al., "Effector and regulatory events during natural killer-dendritic cell interactions," Immunological Reviews, vol. 214, no. 1, pp. 219-228, 2006.

\section{This article should be cited as follows:}

Loredana Frasca and Roberto Lande , "Overlapping, Additive and Counterregulatory Effects of Type II and I Interferons on Myeloid Dendritic Cell Functions," TheScientificWorldJOURNAL, vol. 11, pp. 2071-2090, 2011. 


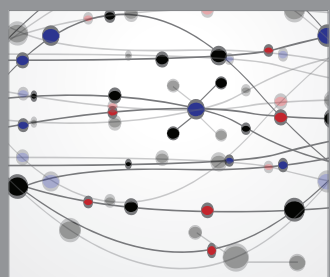

The Scientific World Journal
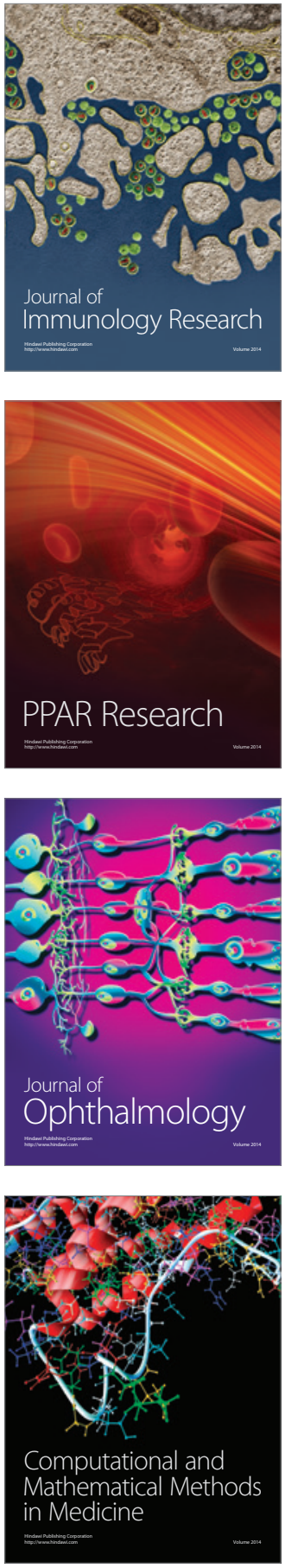

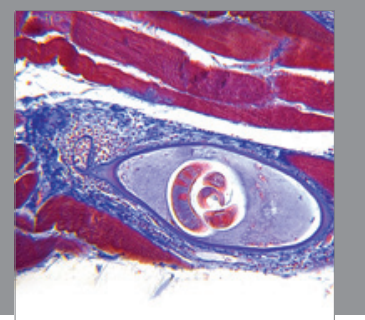

Gastroenterology

Research and Practice
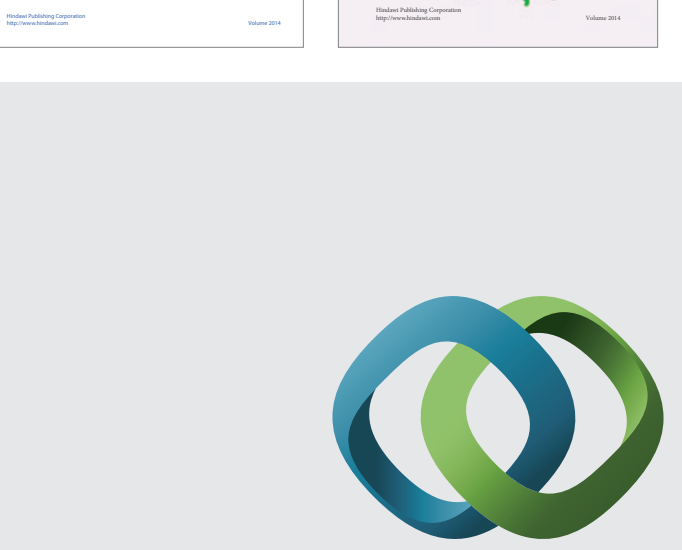

\section{Hindawi}

Submit your manuscripts at

http://www.hindawi.com
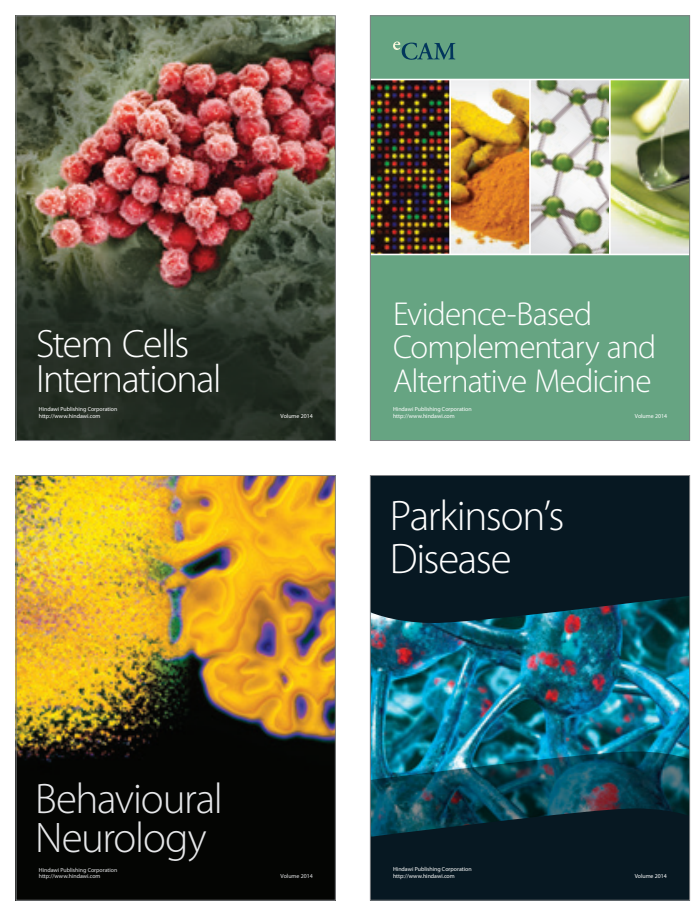

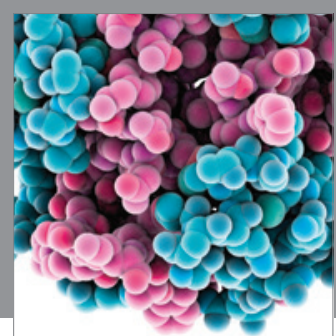

Journal of
Diabetes Research

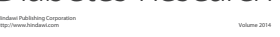

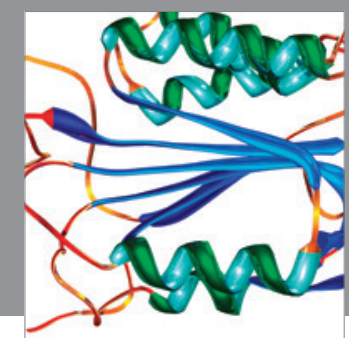

Disease Markers
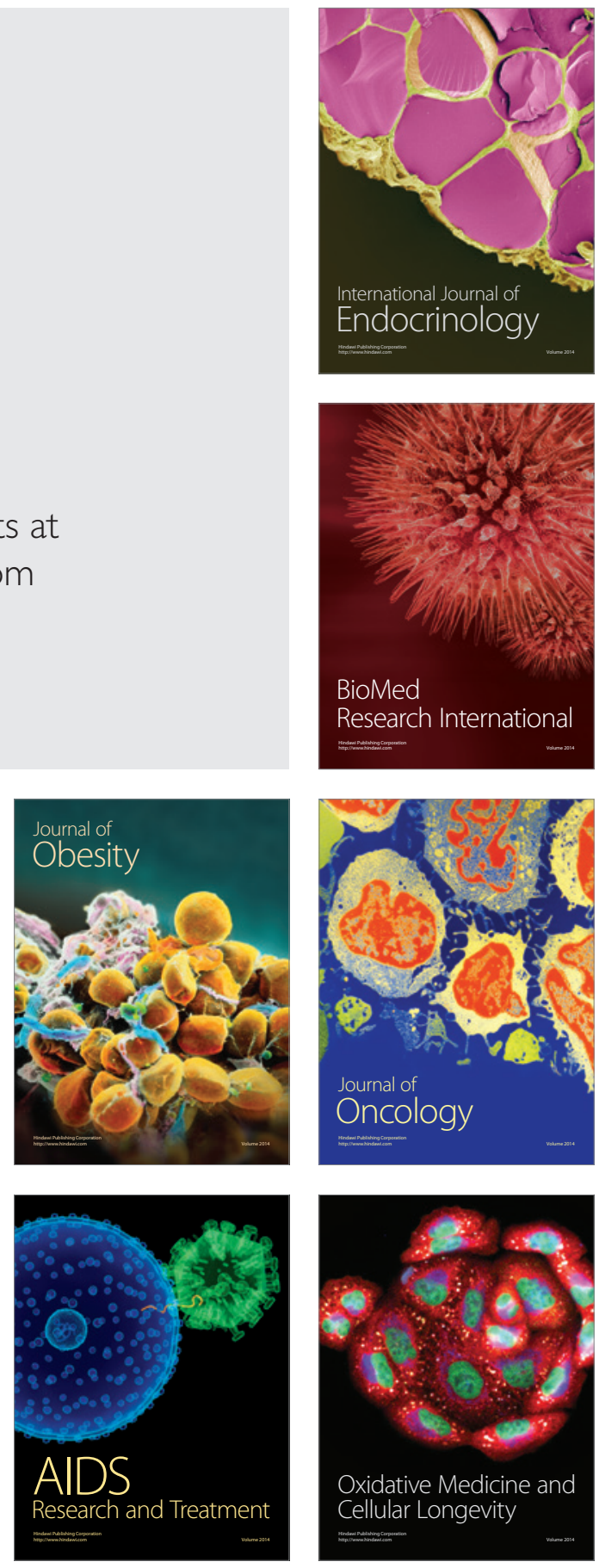